\title{
EDUCAÇÃO AMBIENTAL NA ESCOLA PÚBLICA UNIDADE INTEGRADA GOVERNADOR MATOS CARVALHO, SÃO LUÍS (MA): UM ESTUDO DE CASO
}

\author{
Michelle Menezes Machado ${ }^{1}$ \\ Weline Lopes Macau ${ }^{1}$ \\ Mayara Soares Cunha ${ }^{1}$ \\ Débora de Matos Pereira ${ }^{2}$ \\ Jeremias Guilherme dos Praseres França ${ }^{2}$ \\ Naiza Maria Castro Nogueira ${ }^{3}$
}

RESUMO: Esta pesquisa enfoca um estudo de caso participante realizado em uma escola da rede pública em São Luís (MA). Recursos metodológicos: questionários, palestras, dinâmicas, recursos audiovisuais, oficinas e ação social. Resultados dos questionários: para $88,68 \%$ (pré-teste) e $96,23 \%$ (pósteste) dos alunos, o lixo prejudica o meio ambiente; para $81,13 \%$ (pré-teste) e $90,57 \%$ (pós-teste), aterro sanitário é destino corretos para o lixo; para $77,36 \%$ (pré-teste) e $88,68 \%$ (pós-teste), faz-se dobradura para reutilizar papel; 13,21\% (pré-teste) e $54,72 \%$ (pós-teste) dos alunos sabem quais materiais são separados na coleta seletiva; $81,13 \%$ (pré-teste) e 96,23\% (pós-teste) consideram a Educação Ambiental importante. Observou-se que os alunos apresentaram melhora no rendimento da avaliação final em relação a avaliação inicial.

Palavras-chave: Educação Ambiental; Escola; Lixo.

${ }^{1}$ Graduadas em Licenciatura em Biologia/ Departamento Acadêmico de Biologia/Instituto Federal de Educação, Ciências e Tecnologia do Maranhão. E-mails: michelle_menezes81@hotmail.com; welinizinha@hotmail.com; mayara_301@hotmail.com.

2 Acadêmicos de Licenciatura em Biologia/ Departamento Acadêmico de Biologia/Instituto Federal de Educação, Ciências e Tecnologia do Maranhão. E-mails: solange_mont@hotmail.com; jerry_bass@hotmail.com.

Doutora, Professora do Departamento de Biologia/ Instituto Federal de Educação, Ciências e Tecnologia do Maranhão. E-mail: naiza.maria@globo.com.

Revbea, Rio Grande, V. 8, N²:20-30, 2013. 


\section{INTRODUÇÃO}

A ênfase dada a "evolução" da humanidade criou uma visão de que o homem é o centro diante de todas as outras partes que compõem o ambiente, camuflando a verdadeira realidade, na qual o homem é apenas um dos elementos existentes no meio ambiente e que todos os elementos são interdependentes (GUIMARÃES, 2005).

Com base nessa concepção, adotaram-se práticas, por meio dos processos de industrialização e urbanização, em que a natureza passou a ser vista apenas com a função de servir às necessidades humanas (GUIMARÃES, 2007), passando a ser explorada de forma totalmente descontrolada (SÁNCHEZ, 1981; EFFTING, 2007).

Um dos principais aspectos da problemática ambiental é a relação entre sociedade e natureza. Dentro da sociedade, os seres humanos se organizam e se hierarquizam, ocupando uma determinada posição, na qual, desenvolvem também, diversas formas de relação com a natureza (ABRAMOVAY, 1994). A relação sociedade/natureza pode ser produzida de dois modos: através das ações humanas que incidem sobre o sistema ecológico natural e por meio dos efeitos ecológicos gerados na natureza e que incidem sobre o sistema social (GALLOPÍN, 1986 apud MIOTTO, 2007).

Não se trata apenas de conhecer os processos sociais e naturais de forma isolada, mas sim de saber de que maneira o uso dos recursos existentes pela humanidade interfere em processos naturais que afetam a qualidade de vida dos homens; e de conhecer formas alternativas de utilizar esses recursos para que os impactos negativos do desenvolvimento sejam evitados ou minimizados (ABRAMOVAY, 1994).

No rol das consequências da exploração do meio ambiente pelo o homem está a problemática do lixo, sendo que a solução para esse problema não depende só de questões técnicas, mas também da "visão de mundo" das pessoas; a Educação Ambiental (EA) pode contribuir na construção de uma atitude mais responsável, criando, assim, condições de superação e/ou minimização da degradação ambiental, visando a melhoria da qualidade de vida da população mundial (SILVA et al., 2010).

Carvalho (2008) ainda destaca que a EA deve ser abordada nas escolas de um modo que não a torne apenas mais uma disciplina na grade curricular, mas, sim, um elemento questionador que possa orientar as demais disciplinas para que seus objetivos e conteúdos possam ser repensados, contribuindo para a melhoria da relação ser humano/natureza. É a partir dos questionamentos gerados na EA que o homem passa a se perguntar sobre 0 seu papel no habitat onde está inserido, percebendo que é possível aproveitar os recursos que o meio oferece sem necessariamente destruí-los.

No entanto, apesar do relevante papel da EA, deve-se ter em mente que ela não é a única estratégia a ser utilizada na luta contra a crise ambiental. Se não for combinada com uma política ambiental efetiva, com uma legislação rígida ou com ações voltadas para uma distribuição de renda igualitária,

revista brasileira educação ambiental 
dificilmente ocorrerão mudanças efetivas no atual cenário socioambiental (CARVALHO, 2008).

O presente artigo enfoca um estudo de caso participante realizado na escola da rede pública estadual Unidade Integrada Governador Matos Carvalho, localizada no município de São Luís (MA), durante o período de agosto a dezembro de 2008 e, que contou com a participação de 120 alunos do 5ำ ano do Ensino Fundamental.

O projeto teve como principal meta fazer com que 0 aluno reconhecesse o lixo domiciliar como um sério problema ambiental e baseado na Teoria dos Três R's - reduzir, reutilizar e reciclar - conhecer alternativas para amenizar essa problemática.

\section{METODOLOGIA}

O projeto iniciou-se com a sensibilização dos alunos por meio de exibições de vídeos e música sobre o lixo e a degradação ambiental. Aplicouse um questionário com perguntas objetivas específicas com a finalidade de conhecer o grau de percepção ambiental dos estudantes.

Em seguida, fez-se uma explanação mais especifica a respeito de alguns conceitos de Ecologia e foram realizadas duas oficinas: I - reutilização de garrafas PET (os alunos aprenderam a montar um "puff" com garrafas PET) e II - reciclagem alternativa de papel (demonstrou-se como reciclar papel de modo simples e alternativo) (Figuras $1 \mathrm{~A}$ e B).
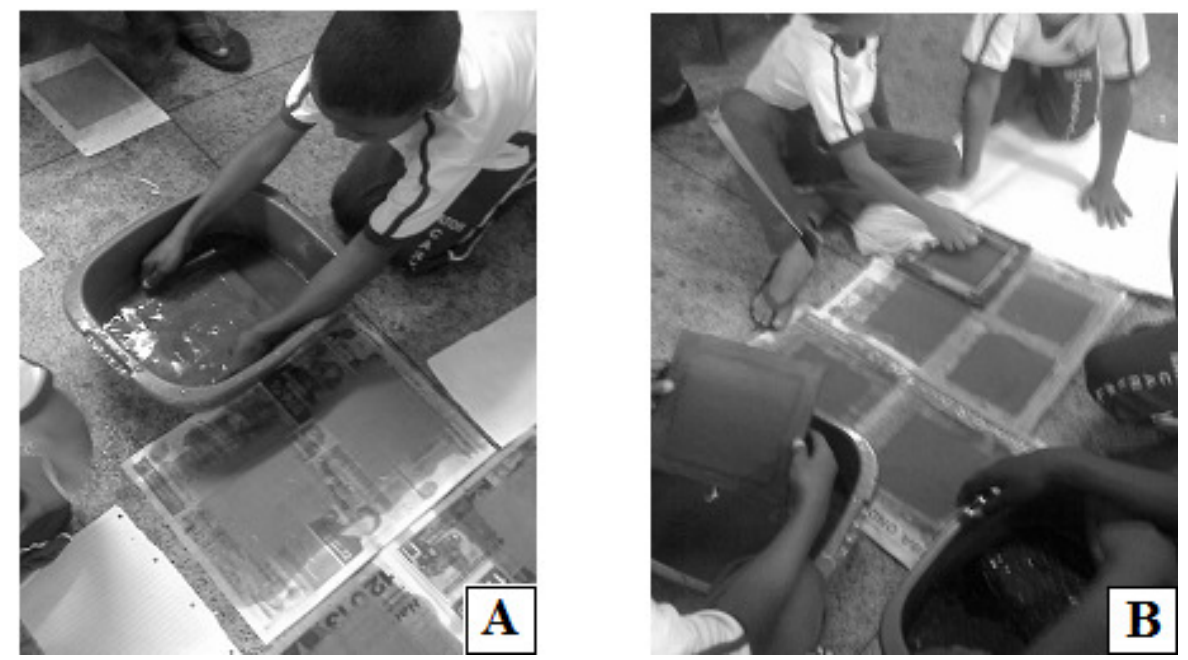

Figuras $1 \mathrm{~A}$ e B: Oficina de reciclagem alternativa de papel. serem utilizados na ação social. 

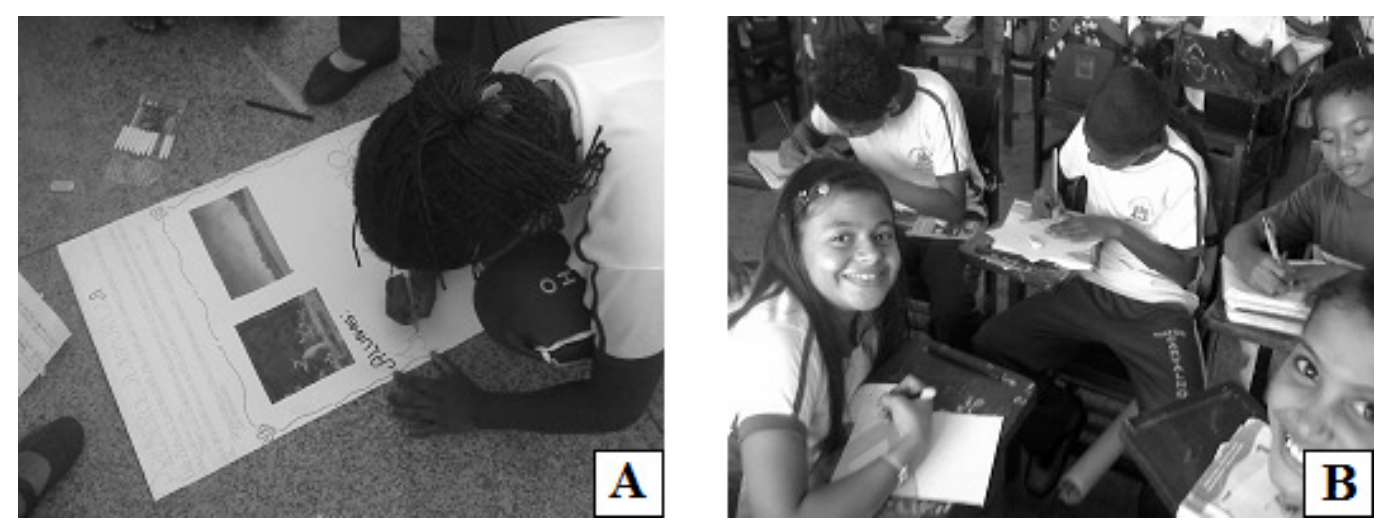

Figuras 2A e B: Confecção de cartazes e produção de panfletos educativos.

Durante a ação social cada aluno ficou responsável por uma atividade: colar cartazes nas salas de aula e nos corredores da escola; distribuir panfletos aos alunos e funcionários; exposição oral do objetivo da ação social; distribuição dos cestos de lixo nas salas de aula; e reafirmação da importância de preservar a escola e o meio ambiente limpo.

Para finalizar, aplicou-se um questionário, igual ao utilizado no primeiro encontro, com o objetivo de comparar os resultados e verificar a efetividade das atividades realizadas com os alunos.

\section{DISCUSSÃO}

Considerando que os princípios da Educação Ambiental sugerem que ela deve partir da realidade do aluno e tendo em vista as características locais, optou-se por enfocar a relação do público-alvo com o meio como ponto de partida para este trabalho. A forma pela qual se abordou o assunto palestras, discussões, dinâmicas, uso de recursos áudio visuais, construção de mural e oficinas, leitura de textos - foi escolhida por acreditar-se que para os alunos o contato mais demorado com a questão ambiental é um dado que pode levá-los a repensar o seu próprio comportamento (MACHADO et al., 2010).

Segundo Guimarães (2003) a abordagem interdisciplinar objetiva superar a fragmentação do conhecimento. Portanto, esse é um importante enfoque a ser perseguido por muitos educadores ambientais, inclusive pela equipe do projeto, já que permite a visão mais geral do ambiente - trabalhar a interação em equilíbrio dos seres humanos com a natureza.

No primeiro encontro trabalhou-se com recursos áudios-visuais. De acordo com Moraes (2006), os meios de comunicação em massa devem ser transformados em um canal privilegiado de educação não somente disseminando informações em bases igualitárias, mas também promovendo intercâmbio de experiências, métodos e valores. Na Conferência de Tbilisi divulgou-se a importância de fazer crescer, através de filmes e de outros meios 
de comunicação, a sensibilidade diante das questões ambientais (EFFTING, 2007).

As animações e a música possuíam linguagem simples, suave e acessível para a faixa etária do público-alvo, permitindo que os estudantes se familiarizassem com o tema do projeto; além disso, alguns filmes abordavam a temática ambiental de forma cômica, o que ajudou a chamar a atenção dos alunos.

Conforme demonstra Guimarães (2007) e Layrargues (1999), os problemas ambientais podem se constituir em temas geradores que questionam e problematizam a realidade; sendo assim, as palestras, nas quais foram mostrados alguns conceitos relacionados ao meio ambiente, permitiram aos alunos conhecer o seu funcionamento e partir daí diagnosticar as alterações ambientais, desenvolvendo atitudes que primem por um ambiente mais saudável.

Nas oficinas de reutilização de garrafas PET (Figuras $3 \mathrm{~A}$ e B) e de reciclagem alternativa de papel, os alunos trabalharam em grupo, propiciando um momento de interação, onde foram trabalhados alguns princípios, como respeito, solidariedade e cidadania.
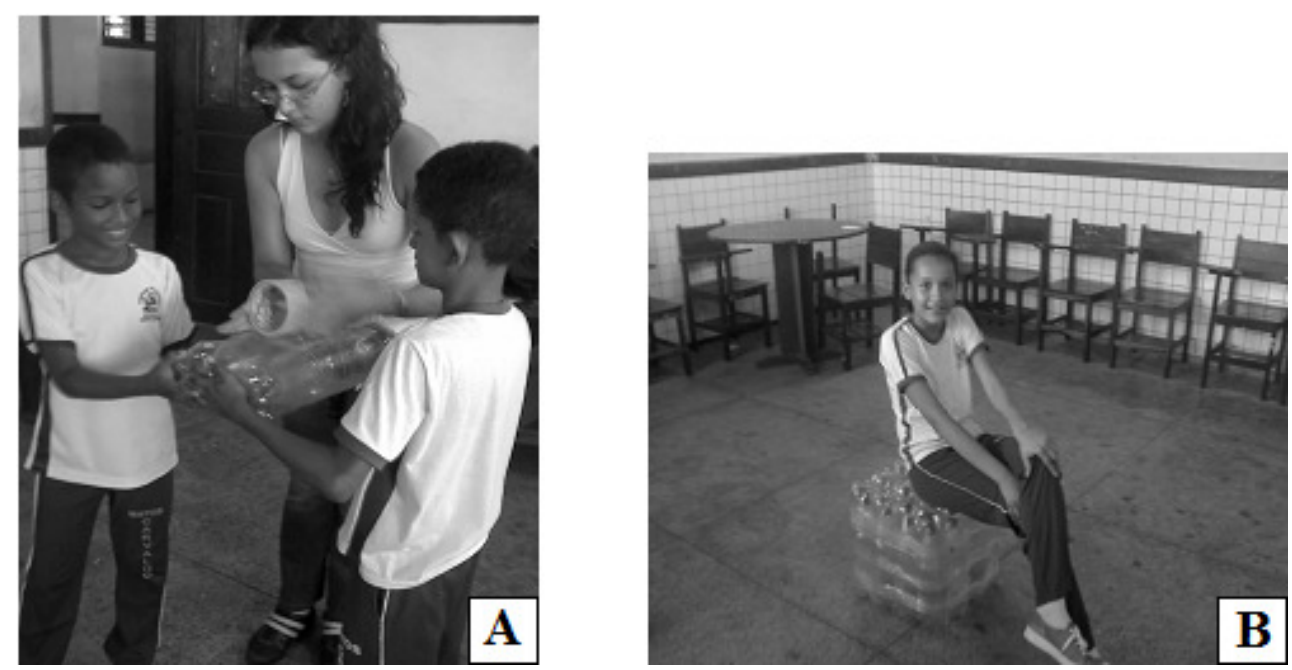

Figuras 3A e B: Oficina de reutilização de garrafas PET.

As oficinas apresentaram resultados positivos no que se refere a mudanças de atitudes das crianças em relação ao meio ambiente: possibilitaram aos alunos maior compreensão da preservação do meio ambiente na utilização e transformação do material reciclado, antes considerado apenas lixo (TEIXEIRA, 2004).

A ação social (Figuras 4A e B) foi importante porque permitiu que os alunos socializassem com a comunidade escolar o que haviam aprendido no projeto.

Revbea, Rio Grande, V. 8, N²:20-30, 2013. 

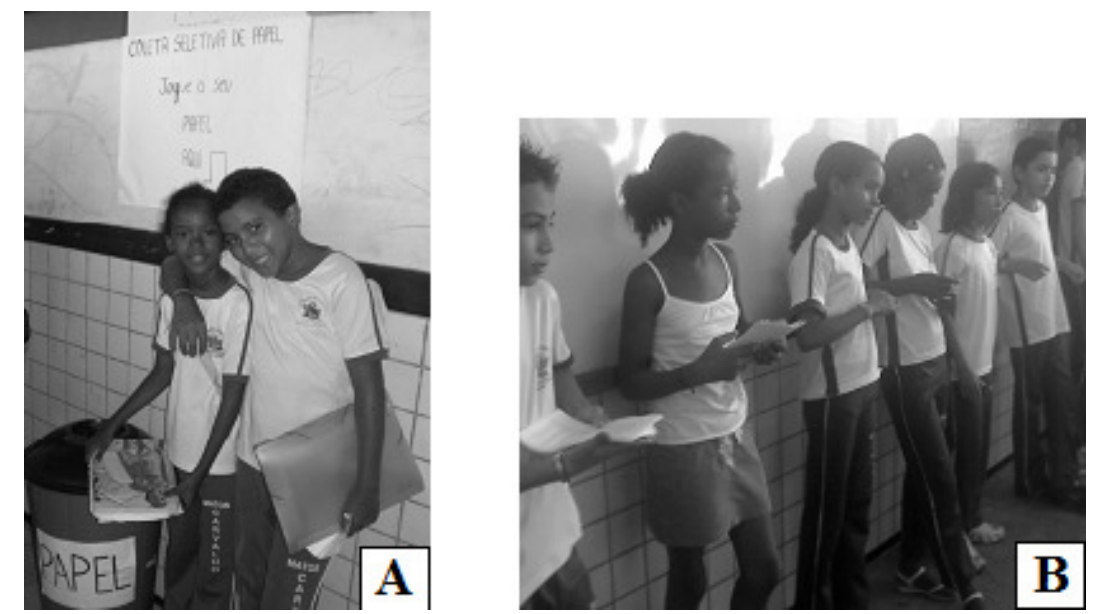

Figuras 4A e B: Ação Social - Distribuição de panfletos, cartazes e cestos de lixo.

No intuito de avaliar a efetividade do projeto, os resultados dos questionários entregues no primeiro (pré-teste) e no último encontro (pós-teste) foram comparados.

Quando questionados sobre o lixo, 88,68\% (pré-teste) e 96,23\% (pósteste) dos alunos responderam que o lixo prejudica o meio ambiente (Gráfico 1). Essa pergunta demonstra que os alunos possuem alguma noção do lixo como agente causador de poluição. Em pesquisa realizada por Torres (2002), com alunos do Ensino Fundamental de São Luís, relatou-se que 92\% dos alunos afirmaram saber o que é poluição, enquanto $8 \%$ não sabem ou não responderam. $O$ fato dos alunos da presente pesquisa saberem que o lixo prejudica o meio ambiente pode ser atribuído aos meios de comunicação como jornais, revistas e televisão, que divulgam a medida do possível, informações sobre Educação Ambiental, visto que na escola não havia nenhum estudo ou projeto na área. Araújo (2005), em pesquisa no município de Balsas, relata que $30 \%$ dos alunos afirmaram obter informações sobre Educação Ambiental através da televisão, jornais e revistas; $20 \%$ através da escola, outros $20 \% \mathrm{em}$ casa e o restante afirmou não ter informações sobre Educação Ambiental.

$\mathrm{Na}$ questão sobre os destinos corretos do lixo, 81,13\% (pré-teste) e 90,57\% (pós-teste) responderam aterro sanitário (Gráfico 2). Cruz et al (2003), em pesquisa semelhante realizada com estudantes de duas unidades escolares em São Luís, demonstrou que a maioria dos alunos conhecia o destino do lixo da sua casa, porém desconhecia o ponto final desses resíduos: lixo coletado pelo serviço municipal $(87,52 \%)$, jogado em terrenos baldios $(1,38 \%)$, queimado $(9,72 \%)$ e jogado em rios $(1,38 \%)$. 


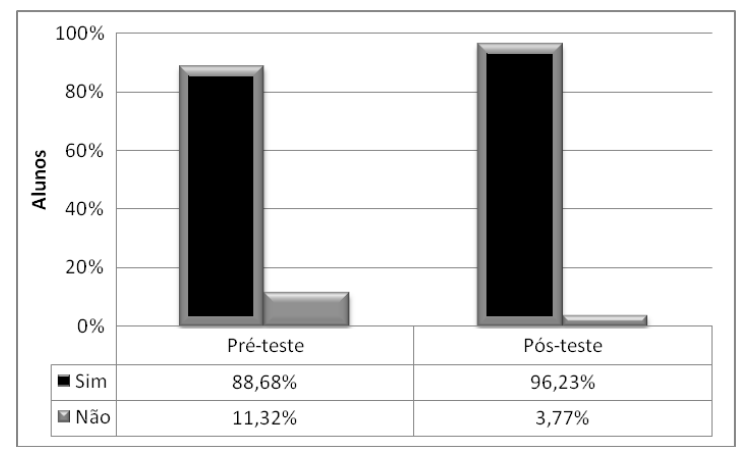

Gráfico 1: Opinião dos alunos em relação ao lixo e o meio ambiente.

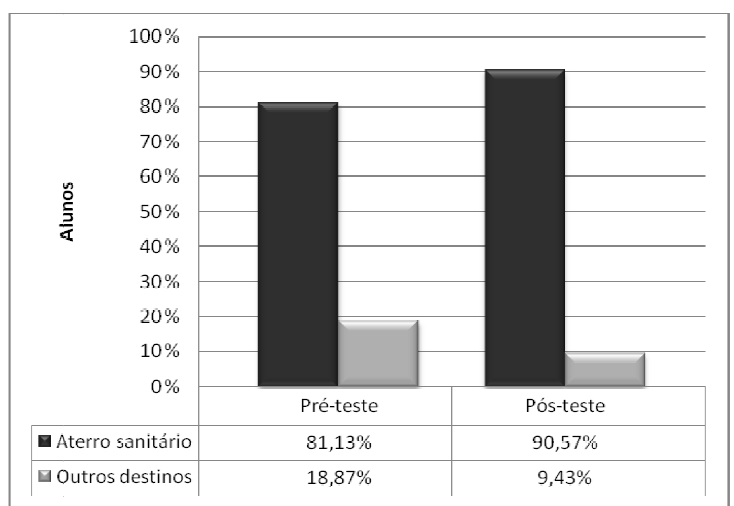

Gráfico 2: Opinião dos alunos em relação ao destino final do lixo.

Sobre a pergunta referente ao que se pode fazer para reutilizar um papel riscado, $77,36 \%$ (pré-teste) e $88,68 \%$ (pós-teste) afirmaram que se pode fazer dobradura como meio de reutilização (Gráfico 3). Verificou-se que $90 \%$ dos estudantes do Ensino Fundamental de um trabalho desenvolvido por Cruz et al (2003), quando abordados sobre a reutilização de embalagens de produtos como garrafas, latas de refrigerantes e sacos plásticos, admitiu reaproveitar as embalagens para outros fins. No que tange a reutilização de materiais, os resultados da presente pesquisa e do trabalho citado são bastante favoráveis.

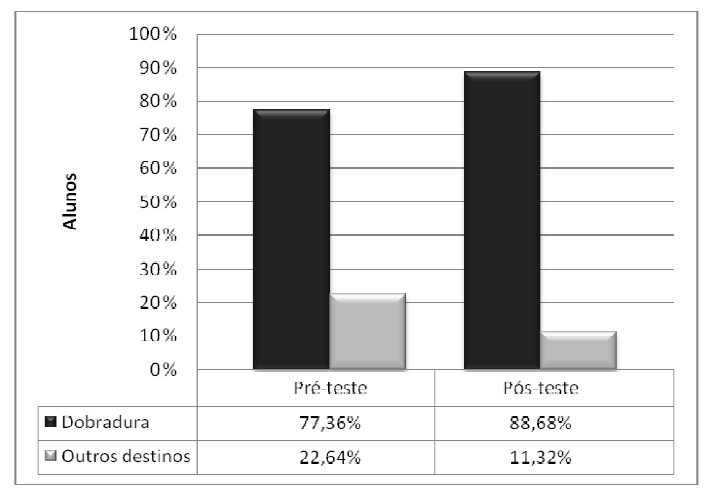


Foi perguntado aos alunos se eles saberiam quais materiais são separados na coleta seletiva, 13,21\% (pré-teste) e $54,72 \%$ (pós-teste) marcaram a opção correta (papel, plástico, metal, vidro e material orgânico) (Gráfico 4).

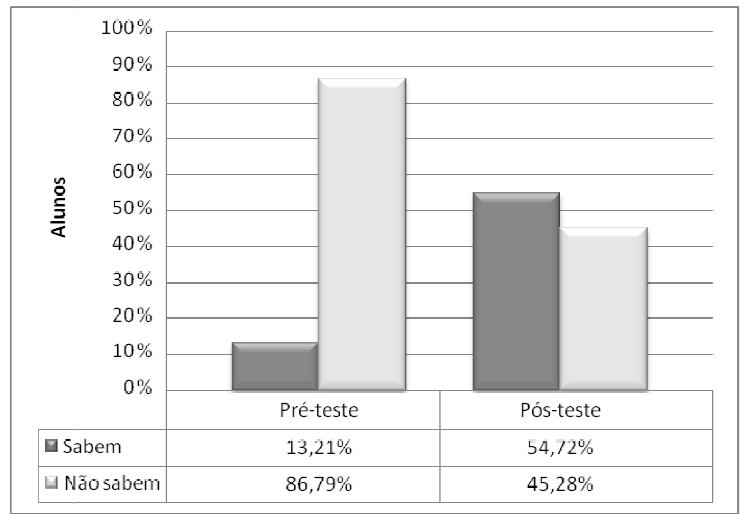

Gráfico 4: Conhecimento sobre os materiais que são separados na coleta seletiva.

Quanto à questão da importância da $\mathrm{EA}$, a maioria da amostra, $81,13 \%$ (pré-teste) e 96,23\% (pós-teste), a considera como sendo importante (Gráfico 5). Araújo (2005), em pesquisa realizada com alunos do Ensino Fundamental do município de Balsas, relata que $60 \%$ dos alunos, quando questionados sobre a EA, a consideraram um tema importante; porém, $40 \%$ dos alunos responderam considerar importantes apenas alguns assuntos ou não souberam responder. Em trabalho realizado por Moraes (2006), na Unidade Integrada Monsenhor Frederico Chaves e Unidade Integrada Prof. Sá Valle em São Luís, 72,5\% dos entrevistados afirmaram possuir alguma informação sobre EA e apenas $27,5 \%$ responderam não possuir. Corrêa (2004), em projeto realizado com alunos Ensino Fundamental do município de São Bento, relatou que todos os alunos afirmaram já terem ouvido falar algo sobre EA. Comparando-se os resultados encontrados no presente trabalho com os apresentados nas referidas pesquisas, observa-se que a maioria dos entrevistados afirmou possuir informações sobre EA, além de considerá-la importante.

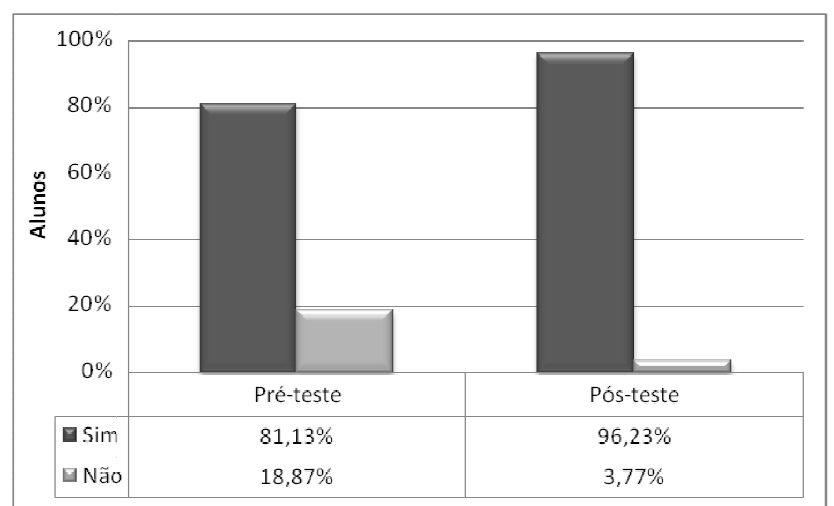

Gráfico 5: Percentual de alunos que consideram a Educação Ambiental importante.

Revbea, Rio Grande, V. 8, N²: 20-30, 2013. 
Nessa questão, pediu-se aos alunos que justificassem a sua resposta. Entre as justificativas mais abordadas destacam-se: para preservar melhor 0 meio ambiente, para ensinar as pessoas a serem responsáveis com o meio ambiente, para aprender que o lixo tem que ser jogado na lata de lixo e não no chão da rua, para preservar a natureza "linda", para ter mais noção de higiene $e$, para diminuir as queimadas e o desmatamento. Tais justificativas revelam o nível de conscientização do quadro discente. Torres (2002), em pesquisa semelhante, relatou que os alunos quando abordados sobre a mesma questão responderam: para preservar a natureza (33\%), para cuidar dos animais e plantas (27\%), para aprender a não jogar lixo nas ruas e não fazer queimadas (12\%). Na pesquisa realizada por Corrêa (2004), foram apresentadas as seguintes justificativas: para nos orientar da importância do meio ambiente $e$ nos ensinar também a preservá-lo, para ensinar as pessoas a tratarem e limparem o meio ambiente, para demonstrar às pessoas a importância do meio ambiente. Alunos do Ensino Fundamental da Unidade Integrada Polivalente de São Luís, afirmam que é importante conhecer e participar das discussões relacionadas às questões ambientais, pois entendem que estas podem contribuir para a melhoria da qualidade de vida - aspectos sócio-ambientais (PEREIRA, 2001).

De acordo com Ruy (2004), implementar a Educação Ambiental na escola é uma tarefa exaustiva. No desenvolvimento desse projeto, houve dificuldades em várias etapas: nas atividades de sensibilização, na implantação de atividades e, principalmente, na continuidade. Fatores como a predisposição dos professores em participarem das atividades e a falta de vontade da diretoria de realmente implementar um projeto ambiental que pudesse alterar a rotina na escola, serviram como obstáculos à implementação da Educação Ambiental.

\section{CONCLUSÃO}

A Educação Ambiental na escola Unidade Integrada Governador Matos Carvalho ainda é superficialmente trabalhada, fato que se reflete, por exemplo, na displicência da comunidade escolar com a grande quantidade de lixo espalhado pelo chão - consequência da falta de cestos de lixo na instituição.

Apesar das inúmeras dificuldades de implantar o projeto na escola, de acordo com o perfil inicial da turma envolvida, acreditamos que os alunos obtiveram apropriação satisfatória do conhecimento através do desenvolvimento do projeto. Partindo da análise comparativa entre os resultados do pré e do pós teste, observa-se o aumento significativo do número de respostas corretas.

De modo geral, nota-se a necessidade de dar continuidade ao trabalho realizado e de se investir pedagogicamente na Educação Ambiental de toda a comunidade escolar, saindo da teoria e partindo para a prática. 


\section{AGRADECIMENTOS}

Ao Programa Institucional de Bolsas de Extensão do Instituto Federal Educação, Ciências e Tecnologia do Maranhão pelas bolsas concedidas às acadêmicas Michelle Menezes Machado e Débora Pereira de Matos. À Unidade Integrada Governador Matos Carvalho.

\section{REFERÊNCIAS}

ABRAMOVAY, M. Género en el manejo de los Recursos Naturales. Costa Rica: UICN, 1994.

ARAÚJO, A.L.A. A educação ambiental em três escolas do ensino fundamental da rede municipal de Balsas. 2005. Monografia (Graduação em Pedagogia). Centro de Educação, Ciências Exatas e Naturais, Universidade Estadual do Maranhão, São Luís, 2005.

CARVALHO, V.S. A ética na Educação ambiental e a ética da Educação ambiental. In: MACHADO, C.; SANCHEZ, C.; ANASTÁCIO FILHO, S.; CARVALHO, V.S.; DIAS, Z.P. Educação ambiental consciente. 2. ed. Rio de Janeiro: Wak, 2008. (Série Educação Consciente).

CORRÊA, L.P.C. Nível de conhecimento dos alunos da Unidade Escolar "Dom Francisco" sobre educação ambiental. 2004. Monografia (Graduação em Ciências Habilitação Biologia) - Centro de Educação, Ciências Exatas e Naturais, Universidade Estadual do Maranhão, São Luís, 2004.

CRUZ, E.C.O. et al. Contribuições da geografia para a educação ambiental a partir do Projeto Protetores da Vida nas unidades escolares João Pereira Martins Neto e Maria Pinho. 2003. Monografia (Graduação em Geografia) Centro de Educação, Ciências Exatas e Naturais, Universidade Estadual do Maranhão, São Luís, 2003.

EFFTING, T.R. Educação ambiental nas escolas públicas: realidade e desafios. Tese (Especialização em Planejamento para o Desenvolvimento Sustentável) Universidade Estadual do Oeste do Paraná, Campus de Marechal Cândido Rondon, Paraná, 2007.

GALLOPÍN, G. Ecologia y ambiente. 1986. In: MIOTTO, L.B. Meio ambiente: intervenção e equilíbrio. Metrocamp Pesquisa, v. 1, n. 1, p. 1-17, jan./jun. 2007.

GUIMARÃES, M. A dimensão ambiental na educação. 5. ed. Campinas, SP: Papirus Editora, 2003.

GUIMARÃES, M. Educação Ambiental: No consenso um embate? 3. ed. Campinas, SP: Papirus Editora, 2005.

GUIMARÃES, M. Educação ambiental: participação para além dos muros da escola. In: MELLO, S.S. de; TRAJBER, R. (Coord.). Vamos cuidar do Brasil: conceitos e práticas em educação ambiental na escola. Brasília: Ministério da Educação, Coordenação Geral de Educação Ambiental: Ministério do Meio Ambiente, Departamento de Educação Ambiental: UNESCO, 2007. 
LAYRARGUES, P.P. A resolução de problemas ambientais locais deve ser um tema-gerador ou a atividade-fim Ambiental? In: REIGOTA, M. (Org.). Verde cotidiano: meio ambiente em discussão. Rio de Janeiro: DP\&A, 1999.

LIMA, B.A.; COSTA, M.A.M.; MORAIS, S.P.; FRIGIERI, T.C. Estudo preliminar da caracterização e quantificação dos resíduos sólidos do município de Itapeva-SP em comparação com municípios da região. In: SIMPÓSIO INTERNACIONAL DE INICIAÇÃO CIENTÍFICA DA USP, 17., 2009, São Paulo. Anais... São Paulo: USP, 2009.

MACHADO, M.M.; CUNHA, M.S.; MACAU, W.L.; PEREIRA, H.K.A.; SILVA, A.F.; PRAZERES, J.G.; NOGUEIRA, N.M.C. Educar para preservar: experiência de Educação Ambiental em uma escola estadual do município de São Luís (MA). Cadernos Temáticos, n. 24, p. 85-90, mar. 2010.

MORAES, A.C.M. A educação ambiental em escolas públicas de ensino fundamental (Unidade Integrada Monsenhor Frederico Chaves e Unidade Integrada Prof. Sá Valle) no município de São Luís - MA. 2006. Monografia (Graduação em Ciências Habilitação Biologia) - Centro de Educação, Ciências Exatas e Naturais, Universidade Estadual do Maranhão, São Luís, 2006.

MORAES, N.A. Aprendendo a preservar o meio ambiente através das mídias. Rio Grande-RS: Universidade Federal do Rio Grande, 2006.

PEREIRA, E.M.A. Nível de conhecimento dos alunos de $6^{\underline{a}}$ a $8^{\underline{a}}$ série da Escola Polivalente sobre a questão ambiental. 2001. Monografia (Graduação em Ciências Habilitação Biologia) - Centro de Educação, Ciências Exatas e Naturais, Universidade Estadual do Maranhão, São Luís, 2001.

SÁNCHEZ, V. Papel de la educación en la interacción entre estilos de desarrollo y medio ambiente. In: SUNKEL, O.; GLIGO, N. (Org.). Estilos de desarrollo y medio ambiente en la América Latina. México: Fondo de Cultura Económica, 1981. p. 590-604.

SILVA, R.A.; SOARES, S.M.V.; SANTANA, R.M. Relação dialética entre teoria e prática sobre Educação Ambiental: um desafio para professores de geografia de um colégio público em Itabuna, BA. Educação Ambiental em Ação, Novo Hamburgo-RS, n. 31, ano VIII, mar./mai. 2010.

TEIXEIRA, L.S.C. Educação Ambiental e Reciclagem de Lixo: Exercício de Cidadania. In: Congresso Brasileiro de Extensão Universitária, 2., 2004, Belo Horizonte. Anais... Belo Horizonte: UCG, 2004.

TORRES, H.S. Manguezal como área de educação ambiental em uma escola de ensino fundamental da rede pública: um estudo de caso. 2002. Monografia (Graduação em Ciências Habilitação Biologia) - Centro de Educação, Ciências Exatas e Naturais, Universidade Estadual do Maranhão, São Luís, 2002. 